\title{
OLHAR PARA DENTRO/OLHAR PARA FORA: LITERATURA NACIONAL E FRONTEIRA
}

\author{
Renato Cordeiro Gomes \\ UERJ
}

Eu também já fui brasileiro

moreno como vocês.

Ponteei viola, guiei forde

e aprendi na mesa dos bares

que o nacionalismo é uma virtude.

Mas há uma hora em que os bares se fecham e todas as virtudes se negam.

(Carlos Drummond de Andrade. "Também já fui brasileiro", de Alguma poesia)

Como eixos que balizam esta reflexão, consideremos duas formulações que procuram tematizar o estatuto da literatura brasileira, enquanto instituição dimensionada no limite material de um sistema em tensão com o seu exterior, gerando valores que instituem a identidade e a representação atra- 
vés de práticas discursivas.

A primeira delas é de Afrânio Coutinho, e a segunda, de Antonio Candido. Eis as citações que nos servem de mote:

I - Há cinco fenômenos que, no Brasil, se destacam como os mais autênticos e importantes, os mais característicos mesmo, do nosso povo: a música popular, o carnaval, o futebol, a religiosidade popular e a literatura. São as expressões mais legítimas do nosso espírito criador, da nossa criatividade. Ninguém, nem nada nesse mundo consegue destruí-las. Tudo o mais fracassa ou não funciona a contento das exigências e necessidades de uma organização civilizatória. Em meio a toda uma desestrutura, aquelas produções surgem soberanas, superando todas as deficiências gerais e dificuldades de vida. É que elas são partidas da alma popular, como suas manifestações legítimas. Não dependem de nada, senão da alma do povo. E esse é espírito e o espírito floresce onde quer. Elas são o próprio povo falando, expressando-se de maneira autônoma, sem qualquer interferência. Convivem com a inferioridade social, com a desorganização geral, até com a pobreza e a miséria. Basta assistir a um carnaval para ficar convencido disso.

Assim acontece com a literatura. Desde cedo, desde as origens que a alma do povo brasileiro se expressa através de literatura. ${ }^{1}$

II - Há literaturas de que um homem não precisa sair para receber cultura e enriquecer a sensibilidade; outras, que só podem ocupar uma parte da sua vida de leitor, sob pena de the restringirem irremediavelmente o horizonte. Assim, podemos imaginar um francês, um italiano, um inglês, um alemão, mesmo um russo e um espanhol, que só conheçam os autores da sua terra e, não obstante, encontrem neles o suficiente para ela-

1. COUTINHO, 1982. p.155-156 borar a visão das coisas, experimentando as mais altas emoções literárias.

Se isto já é impensável no caso de um português, o que se dirá de um brasileiro? A nossa literatura é galho secundário da portuguesa, por sua vez arbusto de segunda ordem no jardim das Musas... Os que se nutrem apenas delas são reconhecíveis à primeira vista, mesmo quando eruditos e inteligentes, pelo gosto provinciano e falta do senso de proporções. Estamos fadados, pois, a depender da experiência de outras letras, o que pode levar ao desinteresse até menoscabo das nossas. ${ }^{2}$

Revela cada texto uma posição antitética em relação ao outro, gerando uma zona tensa, se colocados em confronto. O mútuo contato dos dois textos faz aflorar dicções contrastantes: enquanto Afrânio Coutinho defende a tese nacionalista, Antonio Candido opta pelo cosmopolitismo.

Este contato mútuo torna-se mais rentável, se o contextualizarmos com um texto de Afrânio escrito em 1959 em que critica as posições de Candido. Este artigo $^{3}$ toma o título da própria obra do crítico paulista: "Formação da literatura brasileira" cuja primeira edição é de 1957.

Para contestar a linha adotada por Candido, Afrânio parte dos conceitos de "americanidade" (ou brasilidade), de "autonomia" e "maioridade", através dos quais procura "valorizar a nossa posição em detrimento dos laços de dependência à Europa". De posse da metáfora biológica do crescimento, numa ótica evolucionista, mostra que, desde a virada do século XVI para o XVII, com o Barroco, tivemos os "primeiros vagidos de uma nova alma popular e nacional", num estilo adequado "aos sentimentos da alma brasileira em sua infância". Liberto dos "complexos coloniais", o espírito brasileiro atingiu evolutivamente o amadurecimento, tornou-se adulto. Processo de autonomia marca, então, definitivamente o nosso na-

2. CANDIDO, 1964. $1^{\circ}$ vol., p.9-10.

3. COUTINHO, 1976. p.38-55 
cionalismo. "Hoje o sentimento de nossa autonomia é patente: procuramos pensar por nós mesmos o país que é nosso, no continente cujos problemas só nós sentimos e cuja civilização só nós podemos construir. Um sentimento de maioridade nos domina. Nosso espírito amadurece, tomamos consciência de nós mesmos, pensamos por conta própria, sem a subserviência a padrões, normas e interesses europeus (...)" acrescenta o organizador de $A$ literatura no Brasil. Pelo traço de força que é o nacionalismo, marcamos nossa afirmação como povo e como civilização adquirimos rosto próprio e afirmamos nossa identidade de sujeitonação frente à comunidade universal, sem a "subserviência ao que vem de fora". "Esse é o conteúdo de nosso nacionalismo" - reafirma Afrânio.

Este pensamento de base ufanista descarta a questão da dependência sem, entretanto, enfrentá-la. A questão é camuflada através da "autonomia": a literatura brasileira seria um todo fechado em si mesmo, regendo-se por leis próprias que a caracterizariam. Seus traços autóctones diferenciadores, "sem qualquer interferência", marcariam sua identidade. Querendo combater a unilateralidade que vê a literatura sob o ponto de vista do eurocentrismo, Afrânio cai em outro centramento - o nacionalismo. Combatendo uma unilateralidade com outra unilateralidade, não leva em conta os processos interliterários. Sua miopia nacionalista não o deixa ver que só encarando de frente a dependência, admitindo-a, é que se pode questionála, num jogo dialético entre localismo e universalismo. Não vê que não se trata de uma questão de "resolução" ou "boa vontade", como atesta Durisin, em "Sobre las regularidades del processo interliterário" 4

É por esse "conteúdo de nosso nacionalismo" que contesta a idéia de "formação" da literatura brasileira de Candido que a localiza no século XVIII sob a influência da razão iluminista, quando a literatura brasileira pode ser vista como um "sistema" articulado de autores, obras e público, "em interação dinâmica e de uma certa continuidade da tra-

4. DURISIN, 1987. p.3-9. dição". Para Afrânio, a produção literária já era nitidamente brasileira desde suas origens: as obras anteriores aos nossos árcades não seriam "manifestações" literárias, como quer Candido. "Vem de antes, partiu do instante em que o primeiro homem europeu aqui pôs os pés, aqui se instalou, iniciando uma nova realidade histórica, criando novas vivências, que traduziu em cantos e contos populares, germinando uma nova literatura" (grifo nosso).

Retoma Afrânio, nesta passagem, a teoria da $o b$ nubilação de Araripe Júnior. O europeu esquece a si próprio quando chega aqui e transforma-se no novo homem -- o brasileiro.

Por esse critério, quase uma versão do ius soli do Direito Internacional, nega-se a dependência, para afirmar-se tautologicamente, -- conforme a sugestão de François Jost ${ }^{5}$ para a interpretação popular de literatura nacional, -- que a literatura brasileira é a literatura do Brasil. Ouçamos o que diz Afrânio, quando evoca outros historiadores (Menendez Pelayo, Valbuena Prat e George Brenan), para justificar a sua postura que acusa Candido de subserviente "ao pensamento luso, de todo indigno de um povo culturalmente autônomo", atitude humilde de "velho complexo colonial" que "renuncia a uma parte de nossa cultura" (as manifestações literárias anteriores aos nossos árcades). Diz ele: "(...) literatura espanhola é a que se produz em Espanha e não na América, a despeito do estatuto político existente entre a Metrópole e as colônias da América. É que, exatamente como no caso brasileiro, sem embargo dos laços de dependência política, o espírito de autonomia já se fazia sentir e se desenvolvia largamente, em detrimento da mentalidade do povo colonizador, vale dizer, em favor da formação diferenciada de uma nova ideologia nacional, que se traduzia através da arte, da literatura, da fala, dos costumes e sentimentos novos".

Neste aspecto, encaixa-se como uma luva a irônica definição de literatura nacional dada pelo escritor argentino Ricardo Piglia, em entrevista à $\mathrm{FO}_{\text {- }}$

5. JOST, 1972. p. $13-27$. 
lha de São Paulo (10/07/87). Afirma ele que "literatura nacional seria a tentativa de construir uma tradição que tivesse a forma de uma fronteira. A tradição é fantasiada como se fosse um território, que se pode estabelecer sobre a própria fronteira nacional". O território daria a própria ilusão da autonomia. Territorialidade como traço de legitimação. Ainda ius soli. Deu aqui o primeiro vagido, é brasileiro!

Defende Afrânio, por conseguinte, a existência de uma literatura independente. Propõe uma hierarquização às avessas: privilegia o nacional legitimado pelo popular. Assim como a música popular, o carnaval, o futebol, a religiosidade popular, a literatura é manifestação legítima da alma popular. "Não dependem de nada, senão da alma do povo. (...) sāu o próprio povo falando, expressando-se de maneira autônoma, sem qualquer interferência" -- lemos na citação de $A$ literatura no Brasil, que nos serve de mote. $O$ traço popular, ao lado da territorialidade, cria a ilusão de um sistema de legitimidade próprio, que prescinde de legitimidades externas. A literatura brasileira é pensada como tradição autônoma, desligada das outras, de maneira semelhante à que Ricardo Piglia critica em relação à literatura argentina. Legitimidade gerada pela fronteira que produz a diferença cultural. A retórica nacionalista traça fronteiras.

Afrânio Coutinho tenta, através da tese da autonomia, superar o sentimento de inferioridade da nossa cultura mas confirma, por outro lado, esse mesmo sentimento. Autonomia cultural significa a recusa de "olhar para fora", para além das fronteiras. Querendo ocultar as contradições, não vê que a dependência é inevitável, como mostra Silviano Santiago em "Apesar de dependente, universal"6. A "tradição afortunada" -- tradição em forma de uma fronteira --, não permite a Afrânio ver, como Candido sugere, o "dilaceramento" (semelhante à condição esquizofrênica de nossa cultura, na formulação de Silviano), que "se rege pela dialética do localismo e do cosmopolitismo (...); ora a afirmação premeditada e por vezes violenta do nacionalismo literário, ora o declarado conformismo, a

6. SANTIAGO, 1982. p.13-24. imitação consciente dos padrões europeus" nos diz Candido 7 . Vivendo de tensões e de conflitos, na oscilação entre a identificação com o universal e a afirmação do particular, é no "diálogo de família" (ius sanguinis do Direito Internacional) que "tomamos consciência de nós mesmos". Processo dialético que consiste "numa integração progressiva de experiência literária e espiritual, por meio de tensão entre o dado local (que se apresenta como substância de expressão e os moldes herdados da tradição européia (que se apresenta como forma de expressão)", atesta em outra formulação de Literatura e sociedade ${ }^{8}$

Antonio Candido entrou na mira do alvo da crítica de Afrânio, justamente por negar a autonomia da literatura brasileira, problema que considera superado, só justificável no século passado, quando a jovem pátria procura afirmar-se, como um adolescente, frente ao pai ${ }^{9}$. A Candido interessa estudar "o início de uma literatura propriamente dita, como fenômeno de civilização, não algo necessariamente diverso da portuguesa".

Deste modo, não mascara a questão da dependência. Adotando uma perspectiva histórica, estuda os problemas específicos de nossa literatura e as relações que mantém com outras. Afirma ele, no "Prefácio da $1^{a}$ edição" da Formação..., que a literatura brasileira "gerou no seio da portuguesa e depende da influência de mais duas ou três para se constituir. (...) é galho secundário da portuguesa, por sua vez arbusto de segunda ordem no jardim das Musas". Reconhece, portanto, a dependência e estabelece uma hierarquia que se pode detactar claramente na metáfora da "árvore" dessa citação: dependemos da literatura portuguesa que, por sua vez, depende da literatura ocidental.

Candido vê a literatura como fenômeno de civilização. Começa a enxergar o Brasil a partir da razão iluminista. Por isso vê que nosso "Arcadismo foi importante porque plantou (grifo nosso) de vez a literatura do Ocidente no Brasil, graças aos padrões universais por que se regia, e que permiti-

7. CANDIDO, 1965. p. 131 .
8. Idem, p.132-133.
9. CANDIDO, 1964. p. 30 . 
ram articular a nossa atividade literária com o sistema da civilização a que pertencemos, e dentro do qual fomos definindo lentamente a nossa originalidade" 10 . Com esses padrões universais, fizeram os árcades "poesia civilizada" em que puderam também exprimir as particularidades do nosso universo, e não ficaram presos às manifestações da nossa "alma popular".

Candido trabalha com os valores universais da civilização ocidental, para poder adotar um processo mais seguro de valorização. Processo de hierarquização centrado, portanto, no europeu. Não se prendeu a um volksgeist de que a literatura seria expressão - o que faria cair no ufanismo que acredita na possibilidade de "um pensamento autóctone auto-suficiente, desprovido de qualquer contato alienígena"; como afirma Silviano Santiago ("Apesar de dependente, universal")

"Diálogo de família", a literatura comparada é o caminho para o estudo das literaturas nacionais. Para René Wellek ${ }^{11}$, o grande argumento a favor da literatura comparada, ou geral, ou apenas "literatura", é a "evidente falsidade da idéia de uma literatura nacional contida em si própria. A literatura ocidental, pelo menos, constitui uma unidade, um todo". Para ele, o surto de nacionalidade levou a um cultivo provinciano cada vez mais apertado do estudo das literaturas nacionais -- o que "não passa da expressão de piedosas esperanças, orgulho local e ressentimento contra o poder centralizado". Como fica claro, Wellek, semelhante a Candido, numa postura etnocêntrica, identifica o universal com o ocidental, mas, ao contrário do crítico brasileiro, descontextualiza a questão: o universal é estético, dado pela especifidade do fenômeno literário (a literariedade); nāo leva em consideração as contingências econômico-sociais e político-culturais.

François Jost ${ }^{12}$, por outro lado, pensa a literatura comparada sem o monopólio de um método único. Deve ser ela praticada "segundo as normas de

10. CANDIDO, 1964. p.17. cf. CANDIDO, 1978. cf. GOMES, 1988.p. $117-127$.

11. WELLEK, 1962. p.57-66.

12. JOST, 1972. várias doutrinas, inspirar-se em vários princípios, levar em conta dados diversos". O estudo deve ser crítica e julgamento; deve pôr as obras particulares (das diversas literaturas nacionais) "numa relação recíproca e orgânica e tirar conclusões de ordem geral". Esta seria ainda o universal-ocidental, solo da hierarquização para a valoração. "Na base do comparatismo constata-se a fé na unidade fundamental do fenômeno literário, na negação das autarquias nacionais (na linha de Wellek), não, evidentemente, para privar as literaturas particulares de suas características próprias, uma vez que toda obra nasce de um solo bem determinado de onde elas tiram elementos essenciais de sua substância" (semelhante à posição de Candido). Para Jost, a literatura comparada se dimensiona para além do primeiro conceito de weltliteratur de Goethe que levava em consideração apenas as obras-primas. Sua perspectiva abre-se para a consideração das obras menores e periféricas, ainda que hierarquizadas como "tributária" das "fontes" européias. Galhos secundários de grande árvore ocidental, para retomar a metáfora de Candido.

Este universalismo eurocêntrico é contestado por Etiemble $^{13}$ que, ignorando divisões políticas e limites geográficos, condena, portanto, a perspectiva nacionalista e o provincialismo e mostra que toda literatura particular pode ter a mesma importância que as européias. Combinando investigação histórica e reflexão crítica, considera a "interdependência universal das nações" (Marx) e procura estabelecer a unidade de fundo da literatura como totalidade, ou seja, as invariantes literárias - 0 que permitiria chegar a uma poética comparada.

Outra é a proposta de Durisin ${ }^{14}$ que procura combinar a análise do processo literário com o texto da literatura nacional, com o objetivo de estabelecer categorias da literatura mundial. Para o crítico checo, o traço dominante na evolução dos estudos literários é a conexão entre o historicismo nacional-literário e a evolução da literatura sem seu plano internacional. "A história da literatura nacional reclama, já com sua própria existência,

13. CONGRÈS, 1966. p.5-16.

14. DURISIN, Dionys. Op.cit. 
seu pólo oposto: a história do processo interliterário". De maneira semelhante a Candido, Durisin vê a exigência do processo dialético entre o singular e o universal, do nacional-literário e do interliterário. Ao contrário, porém, do crítico brasileiro, o checo combate o eurocentrismo (retomando a linha que vem de Etiemble e Zhirmunski), a unilateralidade que não deixava aparecer os traços específicos dos domínios extra-europeus. Busca estabelecer que as "comunidades interliterárias", -- não mais hierarquizadas a partir do ocidentaleuropeu, nem das sínteses supra-nacionais --, são "aquelas comunidades de literaturas nacionais que se caracterizam pela mais estreita, a mais direta interação mútua", cuja "especificidade reside em determinadas formas e convenções literárias no passado, e a miúdo também no presente".

Podemos detectar, assim, que Candido não descarta a literatura nacional ("Comparada às grandes, a nossa literatura é pobre e fraca. Mas é ela, não outra, que nos exprime ${ }^{\prime 15}$ ), sem entretanto, considerá-la autônoma e independente, como a vê Afrânio. Por isso, a vê no "duplo processo de integração e diferenciação, de incorporação do geral (no caso, a mentalidade e as normas da Europa) para obter a expressão do particular, isto é, os aspectos novos que iam surgindo no processo de amadurecimento do País" 16 . No dilaceramento entre o local e universal, faz-se uma literatura de "dois gumes". Fica, desta forma, ainda preso ao jogo de fonte e influência, de produção dominante e produção dominada, jogo da imposição da história européia. Nossa literatura é a "adaptação dos padrões estéticos e intelectuais da Europa às condições físicas e sociais do Novo Mundo, por intermédio do processo colonizador", endossa Candido. Ainda não revela como "o texto da cultura dominada retroage sobre o texto da cultura dominante", através de um "processo de expansão em que respostas não-etnocêntricas são dadas aos valores da metrópole ${ }^{17}$, como vêm demonstrando textos de Silviano Santiago.

\footnotetext{
15. CANDIDO, 1964. p.10.

16. CANDIDO, 1987. p. 163-180.

17. SANTIAGO, 1982, p.23.
}

\section{REFERENCIAS BIBLIOGRÁGICAS}

1. CANDIDO, Antônio. A educação pela noite $e$ outros ensaios São Paulo: Ática, 1987. p. 163 - 180: Literatura de dois gumes.

2. Formação da literatura brasileira. 2.ed. São Paulo: Martins, 1964.

3. Literatura e sociedade. São Paulo: Nacional, 1965. p. 131: Literatura e cultura de 1900 a 1945.

4. Literatura e subdesenvolvimento. In: MORENO, César Fernandez (org.). América Latina e sua literatura. São Paulo: Perspectiva, 1978.

5. COUTINHO, Afrânio. Conceito de literatura brasileira. 2. ed. Rio de Janeiro: Pallas, 1976. p. 38 - 55: Formação da litratura brasileira.

6 A literatura no Brasil. 3. ed. Rio de Janeiro: Sul Americana, 1982. v. 1.

7. DURISIN, Dionys. Sobre las regularidades del processo interliterário. Casa de las americas, La Habana, n. 160 , p. 3 - 9, jan./fev. 1987.

8. ETIEMBLE, .Faut - il réviser la notion de weltliteratur? In: CONGRES DE L'ASSOCIATION INTERNATIONALE DE LITTERATURE COMPARÉE, 4, acts... Paris: Mouton, 1966. p. 5 - 16.

9. GOMES, Renato Cordeiro. Para além das fronteiras. Ensaios de semiótica: cadernos de literatura, Belo Horizonte, n. 18/20, p. 117 - 127, dez. 1988.

10. JOST, François. Littérature comparée et littérature universelle. Orbis litterarum, [s. 1.], n. 27, p. 13 - 27, 1972.

11. SANTIAGO, Silviano. Vale quanto pesa; ensaios sobre questões político-culturais. Rio de Janeiro: Paz e Terra, 1982. p. 13 24: Apesar de dependente, universal.

12. WELLEK, René, WARREN, Austin. Teoria 
ENSAIO

da literatura. Trad. José Palla e Carmo. Lisboa: Europa-América, 1962. p. 57 66: Literatura geral, literatura comparada e literatura nacional.

\section{RÉSUMÉ}

Cet essai a comme point de départ deux formulations sur le statut de la Littérature Brésilienne: l'une de Afrânio Coutinho et l'autre de Antonio Candido. Mises en confrontation, elles révèlent des positions opposées, quand elles soutiennent, respectivement, la thèse du nationalisme et celle du cosmopolitisme. Ces propositions revisent des concepts comme identité, autonomie et dépendance de la littérature nationale, ce qui serait une tentative d'établir une tradition qui aurait la forme d'une frontière (ou sa négation). Avec l'aide de la Littérature Comparée, on cherche à mettre en cause la territorialité comme signe de légitimation, engendrée par un système en rapport avec son extérieur. On regarde en deçà et au delà des frontières, pour signaler des différences culturelles dans le dialogue avec d'autres littératures. 